\title{
Comparison of in situ preservation techniques for kidneys from donors after circulatory death: a systematic review and meta-analysis
}

\author{
Alberto Artiles Medina ${ }^{1}$, Francisco Javier Burgos Revilla ${ }^{1}$, Marta Álvarez Nadal ${ }^{2}$, Alfonso Muriel García ${ }^{3}$, \\ Noelia Álvarez Díaz ${ }^{4}$, Victoria Gómez Dos Santos ${ }^{1}$ \\ ${ }^{1}$ Department of Urology, Hospital Universitario Ramón y Cajal, Instituto Ramón y Cajal de Investigación Sanitaria (IRYCIS), Madrid, Spain; \\ ${ }^{2}$ Department of Nephrology, Hospital Universitario Ramón y Cajal, Madrid, Spain; ${ }^{3}$ Department of Biostatistics, Hospital Universitario Ramón y \\ Cajal, Instituto Ramón y Cajal de Investigación Sanitaria (IRYCIS), CIBERESP, Universidad de Alcalá de Henares (UAH), Madrid, Spain; ${ }^{4}$ The \\ Hospital Universitario Ramón y Cajal Library, Madrid, Spain \\ Contributions: (I) Conception and design: A Artiles Medina, V Gómez Dos Santos; (II) Administrative support: None; (III) Provision of study \\ materials or patients: N Álvarez Díaz, V Gómez Dos Santos; (IV) Collection and assembly of data: N Álvarez Díaz, M Álvarez Nadal, A Artiles \\ Medina; (V) Data analysis and interpretation: A Artiles Medina, A Muriel García; (VI) Manuscript writing: All authors; (VII) Final approval of \\ manuscript: All authors. \\ Correspondence to: Alberto Artiles Medina. Department of Urology, Hospital Universitario Ramón y Cajal, Madrid, Spain. Email: alberc.artiles@gmail.com.
}

\begin{abstract}
Background: Several techniques have been developed to reduce the warm ischaemic injury of donation after circulatory death (DCD) organs before procurement. There are scarce data about the in situ preservation techniques for kidney graft outcomes. The aim of this systematic review was to evaluate the best in situ preservation method for kidney graft outcomes from organs obtained from controlled and uncontrolled DCD.
\end{abstract}

Methods: A systematic review of the PubMed (MEDLINE), Embase, LILACS and Cochrane databases was conducted. Studies that compare two or more in situ preservation techniques were identified and included. Only studies which provided enough data to calculate odds ratio were eligible for meta-analysis. PROSPERO registration: CRD42020179598.

Results: The search strategy yielded 7,121 studies. Ultimately, 14 retrospective studies were included. Because of heterogeneity, the included studies provided weak evidence that normothermic regional perfusion (NRP) is the best in situ preservation technique in terms of delayed graft function (DGF) rates. Regarding primary nonfunction (PNF), we carried out a meta-analysis of 10 studies with a pooled OR of 0.83 (95\% CI: 0.40-1.71), for the NRP. In regard to DGF, pooled OR for NRP was 0.36 (95\% CI: 0.25-0.54).

Conclusions: NRP in the DCD donor could improve kidney graft function and be considered the in situ preservation technique of choice for abdominal organs.

Keywords: Donation after circulatory death (DCD); in situ preservation; organ preservation; normothermic regional perfusion (NRP)

Submitted Mar 18, 2021. Accepted for publication Jun 11, 2021.

doi: $10.21037 /$ tau-21-236

View this article at: https://dx.doi.org/10.21037/tau-21-236

\section{Introduction}

Kidney transplantation is the best treatment for patients with end-stage renal disease, as it results in sustained improvement in quality of life compared with dialysis and increases life expectancy. However, this treatment is limited by a shortage of organ, which is currently the greatest challenge facing the field of organ transplantation.

Traditionally, organs for kidney transplants are donated 
after brain death (DBD) - persons declared dead based on neurologic criteria. Nevertheless, there are no sufficient numbers of DBD donors to satisfy the demand for kidneys. In this scenario, kidney donation from donation after circulatory death (DCD) donors has emerged as a valuable strategy to increase the organ donor pool (1). This modality of donation has progressively increased over the last decade and currently accounts for approximately $20 \%$ of deceased donors (2). DCD accounted for $12.9 \%$ of the 30,312 donors reported to the Global Observatory on Organ Donation and Transplantation in 2018.

DCD donation can be divided into both controlled and uncontrolled donation. Controlled DCD (cDCD) refers to donation from persons whose death has occurred following the decision to withdraw life-sustaining therapies (WLST) that are no longer considered to be in the best interests of the patients. Uncontrolled DCD (uDCD) refers to donation from persons who die as a result of an unexpected and sudden cardiac arrest for which resuscitation has been unsuccessful (2). The quality of organs retrieved from deceased donors varies, and therefore, they are classified into two groups: standard-criteria donors (SCD) or extended-criteria donors (ECD) (3).

The main difference between DCD and DBD organs is the duration of warm ischaemia. Warm ischaemia commences when there is inadequate oxygenation or perfusion of the organ as defined by a systolic arterial pressure (SAP) $<50 \mathrm{mmHg}$, oxygen saturation $<70 \%$, or both, such as during withdrawal of treatment or cardiac arrest. The period of warm ischaemia continues until the initiation of cold perfusion. By definition, DCD will incur some degree of warm ischaemia as there will be an interval after asystole when organs are not being perfused and have not yet been cooled. As a consequence, organs from DCD donors have the potential to develop irreversible damage due to the accumulation of ischaemic metabolites (4).

Organ procurement from DCD donors is complex and requires the development of new strategies for organ preservation. The processes of warm and cold ischaemia threaten the viability of DCD organs, but these risks can be minimized by well-organized DCD pathways and new techniques of in situ organ preservation and ex situ resuscitation. According to the medical literature, transplantation survival after DCD is comparable to donation after brain death, although it has higher rates of primary nonfunction and delayed graft function. Several countries have successfully implemented DCD programs thanks to national ethical, professional and legal frameworks (5).
Standard DCD organ recovery involves a super rapid technique, with cold thoracic and abdominal perfusion. However, the conventional methods of preservation based on static and hypothermic storage may not be the most appropriate for DCD grafts, especially in the presence of long warm ischaemia times. New strategies have been designed to improve the preservation of in situ DCD grafts, including the use of normothermic regional perfusion (NRP) for abdominal organs and concomitant cold lung flushing. The use of in situ NRP is a significant advance in abdominal organ retrieval, and it has the potential to increase organ recovery rates due to its applicability in both controlled and uncontrolled DCD donors (6).

There are different legal frameworks across countries. For example, in Europe, DCD is practiced in 18 countries: 8 countries have both $\mathrm{cDCD}$ and uDCD programs, 4 countries only have cDCD programs and 6 countries only have $\mathrm{uDCD}$ programs. The no-touch period ranges from 5 to $30 \mathrm{~min}$. Moreover, there are variations in ante (heparinization and femoral vessel cannulation) and postmortem interventions used for the practice of cDCD. During 2008-2016, the countries with the highest DCD activity were the United Kingdom, Spain, Russia, the Netherlands, Belgium and France (7). Although there is diversity among DCD programs, Australia, Israel, China, the United States, and Canada also have DCD programs. In fact, for example, in the United States, the number of DCD donors has more than doubled from 791 DCD donors in 2007 to 1,880 donors in 2017 (8).

Finally, all countries where NRP is performed resort to the occlusion of the aorta, either by surgical clamping or using an aortic balloon, to avoid restoring circulation to the brain after the determination of death. Legislative obstacles and ethical concerns constitute the main barriers to the development of new DCD programs.

This issue has scarcely been addressed in the medical literature, and only a few authors have comparatively analysed the different in situ preservation techniques and their impact on the outcome of kidney transplantation. For example, Barrou et al. described the two methods using an extracorporeal membranous oxygenation (ECMO) circuit and the experience reported by several transplantation groups in this field. The authors note that research studies on this topic suffer from methodological limitations, such as retrospective analysis, small cohorts, and noncomparative studies. In addition, Barrou indicates that, based on the experimental rationale, many groups would not perform randomized studies comparing different techniques. Another 
identified obstacle is that normothermic regional perfusion can be considered mandatory for liver procurement in many protocols (9).

\section{Types of in situ preservation techniques}

Ex situ machine perfusion and in situ regional perfusion in the donor are emerging as potential tools to preserve vulnerable grafts. There are several methods of kidney in situ preservation including:

\section{Cold in situ perfusion (ISP) or in situ cooling (ISC)}

It is a technique consisting of cooling the organs in situ as quickly as possible, using a double-balloon triplelumen catheter, inserted in the femoral artery to infuse a cold preservation solution at the abdominal level. Blood is drained through a large venous cannula inserted in the femoral vein. The temperature decrease is not optimal, as the abdomen remains closed at this stage (donation consent has not yet been obtained), and there is no topical cooling. No oxygen is added to the perfusion circuit. The volume of solution to perfuse is significant (approximately 15-20 L).

\section{Total body cooling (TBC)}

This preservation method consists of cooling the organs as quickly as possible using an extracorporeal membranous oxygenation (ECMO) closed circuit (using donor blood). The cannulas are inserted in the femoral vessels. In contrast to the first technique, oxygen is added to the perfusion circuit.

\section{Normothermic regional perfusion or normothermic ECMO (NECMO)}

This technique allows the perfusion of the organs in normothermia first with donor blood using an ECMO circuit. Organs are subsequently cooled down in situ using the same circuit. The concept of normothermic perfusion arose in 1997 with the publications of Arias Diaz, Gonzales and Tabet et al., demonstrating the beneficial effect of normothermic reperfusion with donor blood to restore the energetic status of the cells, in a pig liver transplantation model. However, the first application of normothermic reperfusion in humans was performed in the field of kidney transplantation from uncontrolled DCD. The first application in human liver transplantation was performed later by the group of Barcelona (Spain), which started the program in 2002 (9).

\section{Hypothermic regional perfusion (HRP)}

It is another type of abdominal regional perfusion (ARP). Depending on the temperature, we can distinguish between normothermic regional perfusion (NRP) or HRP. In HRP, the temperature of the diluted blood solution is cooled to anywhere from 4 to approximately $20^{\circ} \mathrm{C}(10)$.

\section{Super rapid recovery (SRR)}

This method is used to recover $\mathrm{cDCD}$ organs. Once death has been declared, the surgical team performs midline laparotomy to cannulate the distal abdominal aorta, clamp the supraceliac aorta, and flush the cold preservation solution, which is vented through the inferior vena cava (11).

We present the following article in accordance with the PRISMA reporting checklist (available at https://dx.doi. org/10.21037/tau-21-236).

\section{Objectives}

Our systematic review and meta-analysis aimed to assess which is the best in situ preservation method for kidney graft outcomes from organs obtained from controlled and uncontrolled donors after circulatory death (DCD).

\section{Methods}

The protocol for this systematic review with meta-analysis was registered with PROSPERO (CRD42020179598). We used the PICO framework (P: population, I: intervention, $\mathrm{C}$ : comparator and $\mathrm{O}$ : outcome) to establish our clinical question and design our search strategy.

\section{Inclusion and exclusion criteria}

The detailed inclusion criteria were as follows: (I) experimental studies, randomized or nonrandomized, and/ or observational studies; (II) comparative studies; (III) comparison of two or more in situ preservation techniques; (IV) comparison of outcomes in recipients transplanted from uncontrolled DCD (Maastricht categories I and II DCD donors) and/or controlled DCD donors (Maastricht categories III and IV DCD donors); and (V) analysis of at least one of the following outcomes in human kidney grafts: graft loss, graft survival, primary nonfunction (PNF), delayed graft function (DGF) or graft rejection.

The exclusion criteria were as follows: (I) noncomparative studies or irrelevant to the subject; (II) editorials, meeting abstracts, letters to the editor, review articles, case reports, 
and animal experimental studies; and (III) literature with no extractable date.

\section{Literature search strategy}

A systematic review of the literature was carried out in the following databases without language or temporal restrictions: PubMed (MEDLINE), Embase, LILACS and Cochrane Central. The full search strategies are outlined in the Appendix 1. These strategies were performed on April 14-15, 2020.

Furthermore, we searched for conference abstracts of organ transplantation symposia, including the European Society for Organ Transplantation (ESOT) Congress $\left(17^{\text {th }}\right.$ 2015 to $19^{\text {th }}$ edition 2019), the American Transplant Congress (ATC) - 2017 to 2019, the Congress of the International Society for Organ Donation and Procurement-ISODP $\left(14^{\text {th }}\right.$ edition 2017 to $15^{\text {th }}$ edition 2019), the European Association of Urology (EAU) Congress-32 ${ }^{\text {nd }}$ Annual Congress 2017 to $34^{\text {th }}$ Congress 2019, and the Congress of the "Asociación Española de Urología" (AEU) —2017 to 2019.

Moreover, we checked the bibliographic references to additional relevant studies and searched OpenGrey for grey literature. We also contacted some experts in this field to obtain additional information on the in situ preservation techniques.

\section{Data extraction and review}

Two review authors independently screened results obtained from the search to determine whether they fulfilled the eligibility criteria of this review, and we used a consensus method. A third author was consulted if there were disagreements.

Two independent reviewers extracted study data into a predetermined template for the following parameters:

(I) Author(s), study date and period, center(s);

(II) Study design;

(III) Participant characteristics: donor patients/ transplants, eligibility criteria, details of preservation technique used;

(IV) Outcomes reported: graft survival (12 months) and graft rejection; primary nonfunction (PNF), defined as permanent lack of graft function from the time of transplantation. Delayed graft function (DGF) is defined as the need for dialysis during the first week after transplantation and is a manifestation of acute tubular necrosis (ATN). Graft loss was defined as the absence of kidney function, occurring any time after transplantation due to either patient death or irreversible graft injury requiring chronic dialysis and/or retransplantation;

(V) Follow-up period;

(VI) Missing data.

\section{Risk of bias (quality) assessment}

We used the Newcastle-Ottawa Scale (NOS) to assess the quality of nonrandomized studies; it assesses bias in the domains of representativeness of the exposed cohort, the selection of the nonexposed cohort, ascertainment of exposure, the comparability of cohorts, the assessment of outcomes and follow-up timing and attrition.

We did not assess publication bias using Egger's regression or symmetry of funnel plots because there were no more than 10 studies combined in each meta-analysis.

\section{Statistical analysis}

The review tabulates quantitative information and systematic descriptions of all studies included.

We determined the measures of association (OR) using data reported in each study. Meta-analyses were conducted using studies with directly comparable groups, as determined by the types of in situ preservation techniques used. Only observational studies were included in metaanalyses, as there were no RCTs with comparable groups eligible for meta-analysis. Odds ratios (ORs) between two comparable groups were estimated using Dersimonian Laird random effects models. Heterogeneity was evaluated using the $\mathrm{I}^{2}$ statistic, and $\mathrm{I}^{2}$ thresholds of $<25 \%, 25-49 \%$, $50-75 \%$ and $>75 \%$ were considered to represent low, moderate, high, and very high heterogeneity, respectively. Odds ratios (ORs) and their 95\% confidence intervals were calculated and pooled through the STATA 15.0.

\section{Results}

A total of 7,121 studies (after removal of duplicates) were found in databases. After initial screening, 88 studies were considered potentially relevant. A further screening of abstracts and full texts was conducted, and a final sample of 14 studies was considered relevant to our review.

The comparability between in situ preservation techniques in relation to five outcomes has been explored, covering the most important graft outcomes. Primary nonfunction of 

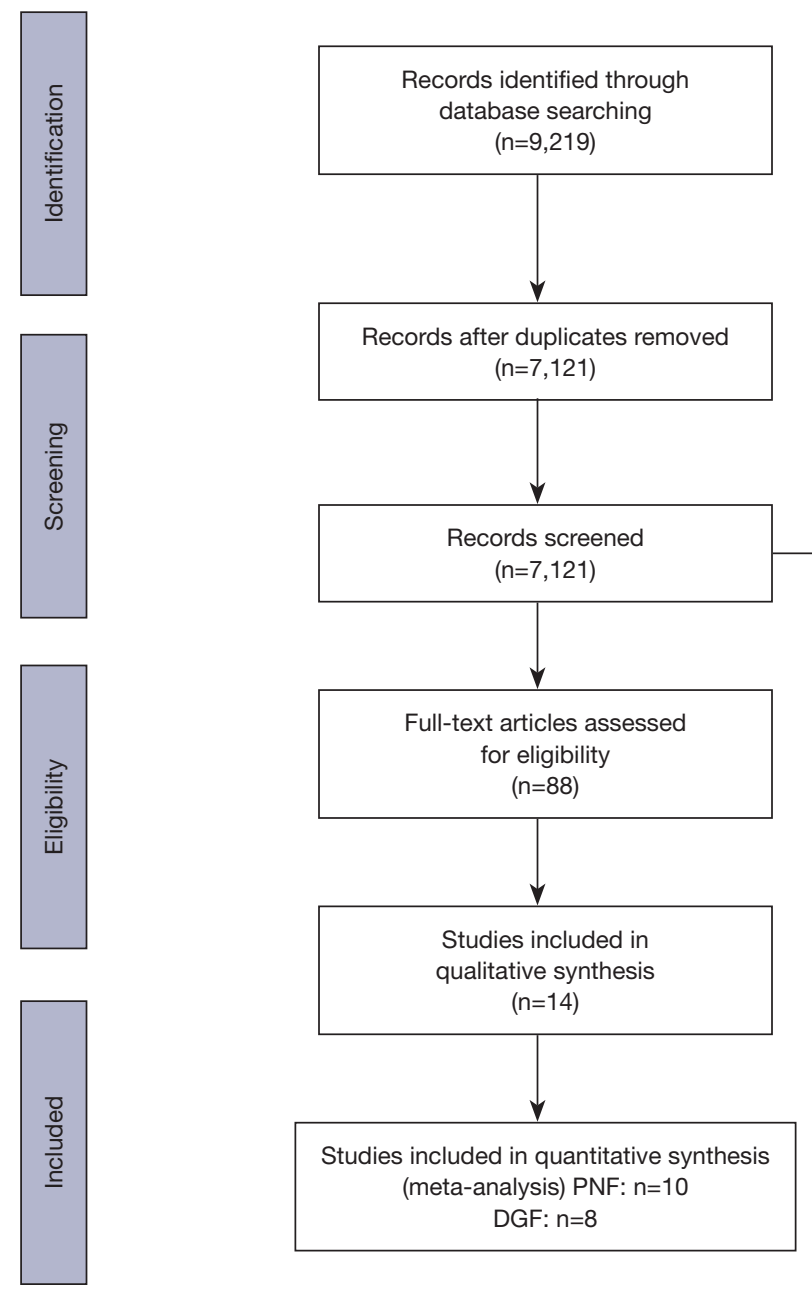

Figure 1 PRISMA flow diagram for systematic review of the comparison of in situ preservation techniques in DCD. DGF, delayed graft function; PNF, primary nonfunction.

kidneys and delayed graft function were also examined by meta-analyses of observational studies. Figure 1 shows the PRISMA flow diagram, which depicts the flow of information through the different phases of our systematic review.

All but two of the studies were retrospective evaluations of patient records; the two non-retrospective studies were observational case control studies. In general, the selected studies were conducted in countries with a predominant DCD activity in Europe (France, Spain, and The Netherlands).

The outcome data of studies included in the systematic review of in situ preservation techniques were as follows:

\section{Primary nonfunction of kidneys}

Of the 12 studies that included PNF of kidneys as outcome
(Table 1), only 10 provided sufficient data for meta-analyses. Kidney allografts preserved using in situ cooling had higher PNF rates than allografts preserved with NRP in the series of Del Rio et al. Nevertheless, the pooled OR does not show difference between the two groups.

PNF rates were similar in allografts perfused using NRP and allografts perfused using super rapid recovery; there was no significant difference. Because of the variability in comparison groups (types of DCD and preservation technique) and reported statistical data, it is difficult to make conclusions about the best preservation method.

Figure 2 shows the forest plot of the meta-analysis of different techniques. For NRP $v s$. ISC (group 3 in the forest plot), the pooled OR was 0.73 (95\% CI: 0.28-1.94). For the comparison between NRP and SRR (group 4), the pooled OR 
Table 1 Included studies regarding PNF

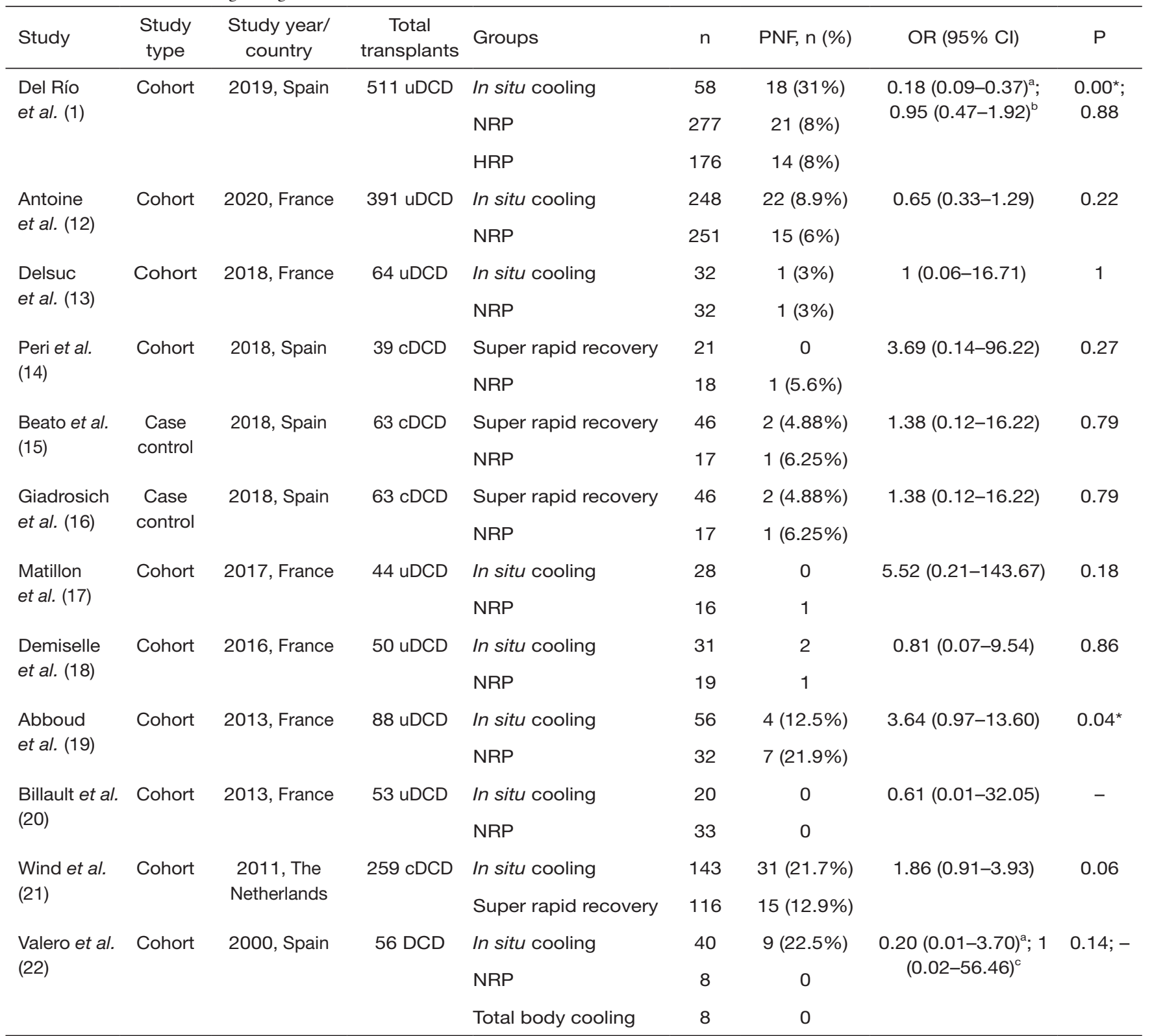

${ }^{a}$, normothermic regional perfusion versus in situ cooling; ${ }^{b}$, normothermic regional perfusion versus HRP; ${ }^{~}$, normothermic regional perfusion versus TBC. *, $\mathrm{P}<0.05$. CDCD, controlled donation after circulatory death; uDCD, uncontrolled donation after circulatory death; NRP, normothermic regional perfusion; HRP, hypothermic regional perfusion.

was 1.97 (95\% CI: 0.28-14.09). The random effects metaanalysis of the direct evidence from 10 observational studies provides an overall odds ratio of 0.83 (95\% CI: $0.40-1.71$ ).

\section{Delayed graft function}

Valero et al. (22), Demiselle et al. (18) and Del Río et al. (1) have published results indicating the benefits of NRP over ISP. Etchevarry Giadrosich et al. (16) and Beato et al. (15) found significant differences between SRR and NRP. The study of Peri et al. did not reveal any significant differences between these preservation techniques. Table 2 summarizes DGF outcomes and Figure 3 shows the forest plot of meta-analysis. The overall pooled OR for NRP was 0.36 (95\% CI: $0.25-0.54$ ). 


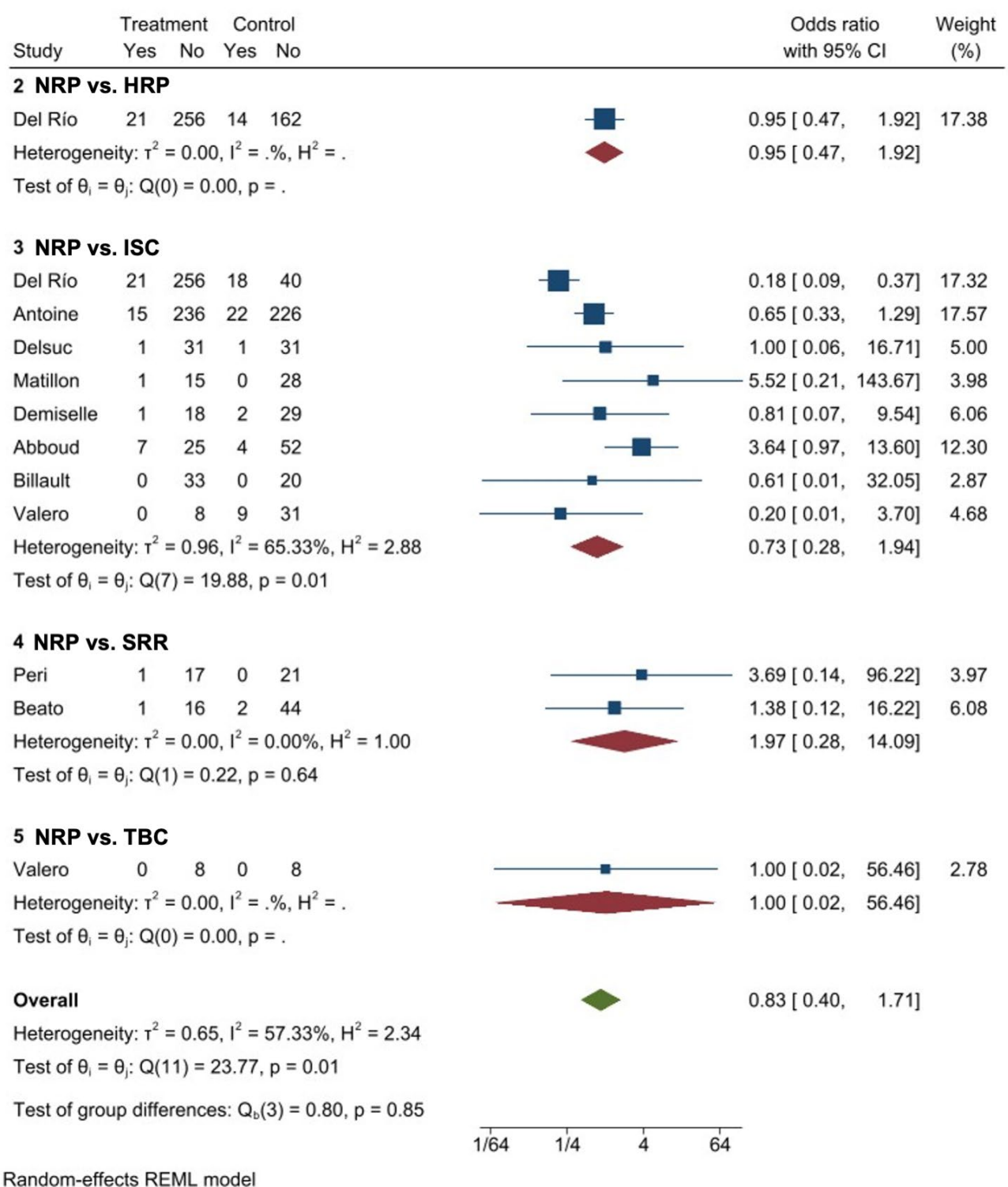

Figure 2 Forest plot of meta-analysis regarding primary nonfunction (PNF). Group 2: NRP vs. HRP, Group 3: NRP vs. ISC, Group 4: NRP vs. SRR, Group 5: NRP vs. TBC. HRP, hypothermic regional perfusion; ISC, in situ cooling; NRP, normothermic regional perfusion; SRR, super rapid recovery.

\section{Graft loss during the first year after transplantation}

Only a few studies have focused on this outcome (Table 3). Del Río et al. (1) determined that NRP has lower graft loss rates than ISP (OR 5.6, 95\% CI: 2.7-11.5).

\section{Kidney graft survival at 24 months}

There were no differences between preservation groups in the three studies included in the review, as shown in Table 4.

\section{Acute rejection}

In the field of in situ preservation, this outcome remains poorly studied (Table 5).

\section{Quality assessment}

The Newcastle-Ottawa Scale was used to evaluate the quality of each of the included studies. Table 6 shows the NOS assessments of evidence quality. 
Table 2 Articles included in the review in relation to DGF outcomes

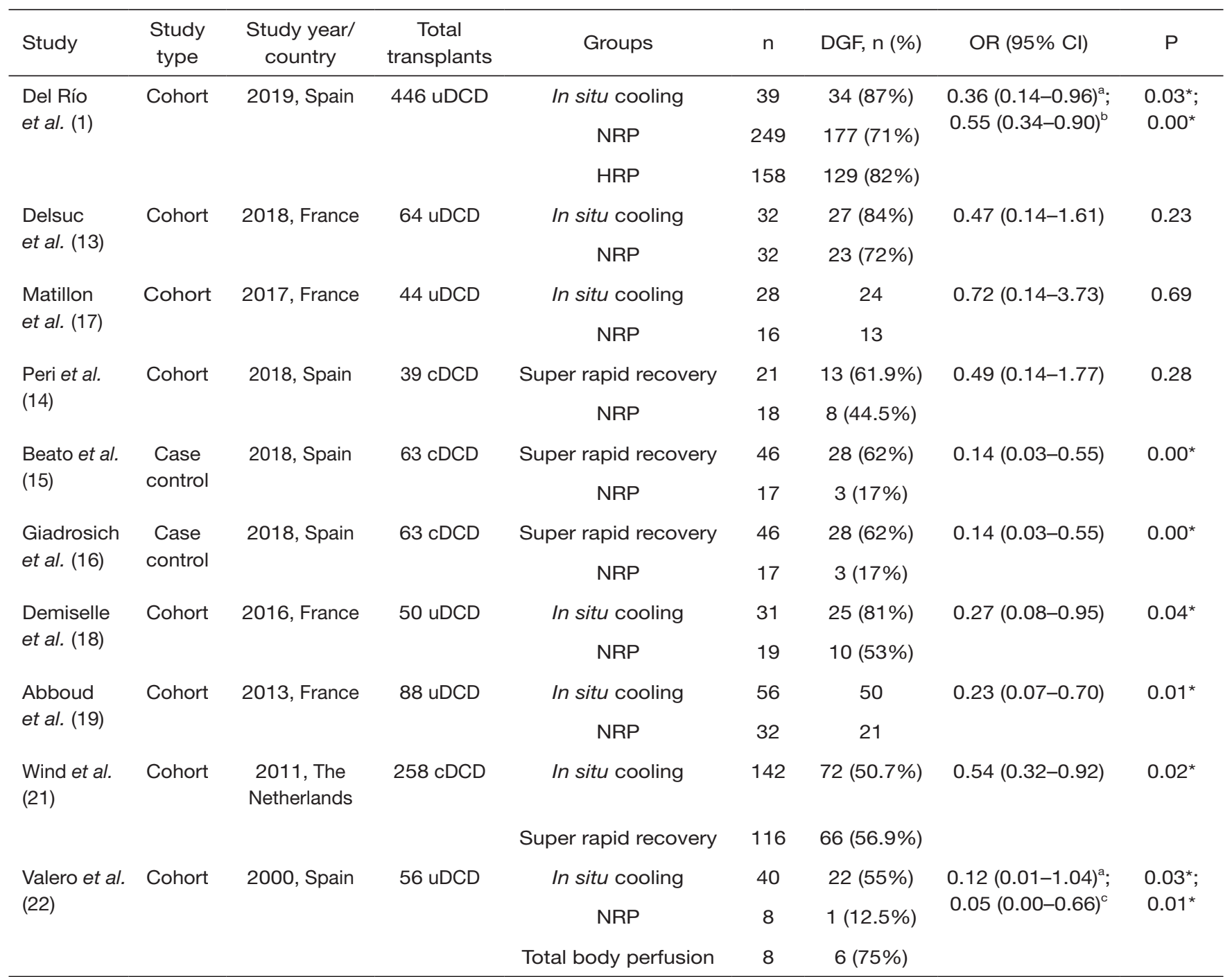

${ }^{a}$, normothermic regional perfusion versus in situ cooling; ${ }^{b}$, normothermic regional perfusion versus HRP; ${ }^{c}$, normothermic regional perfusion versus total body perfusion. * $\mathrm{P}<0.05$. cDCD, controlled donation after circulatory death; uDCD, uncontrolled donation after circulatory death; NRP, normothermic regional perfusion; HRP, hypothermic regional perfusion.

\section{Discussion}

Contrary to liver transplantation, few data have been published in the literature on the field of in situ preservation of kidneys in DCD. NRP has been well established internationally to have good outcomes for liver DCD grafts. For example, Peng et al. conducted a systematic review and meta-analysis to determine whether extracorporeal membrane oxygenation (ECMO) in liver transplantation could improve DCD recipients' outcomes compared with donors after brain death (DBD) recipients. He concludes that ECMO makes 1-year patient survival acceptable in
DCD recipients. The 1-year graft survival rate was lower in DCD recipients than in DBD recipients (24). In the field of pancreas transplantation, NRP is the only other preservation technique that has been used clinically apart from static cold storage, and a small number of studies of pancreas preservation using NRP have been reported (25).

Shapey et al. undertook a systematic review, including liver and kidney graft results using regional perfusion (RP). Significant heterogeneity between the studies meant that a meta-analysis was not appropriate. They reported 1-year patient and graft survival rates better with RP-DCDs vs. 


\begin{tabular}{|c|c|c|c|c|c|}
\hline Study & $\begin{array}{l}\text { Treatment } \\
\text { Yes No }\end{array}$ & $\begin{array}{l}\text { Control } \\
\text { Yes No }\end{array}$ & & $\begin{array}{l}\text { Odds Ratio } \\
\text { with } 95 \% \mathrm{Cl}\end{array}$ & $\begin{array}{c}\text { Weight } \\
(\%)\end{array}$ \\
\hline \multicolumn{6}{|c|}{2 NRP vs. HRP } \\
\hline Del Río & $177 \quad 72$ & 12929 & & $0.55[0.34,0.90]$ & 33.54 \\
\hline \multicolumn{3}{|c|}{ Heterogeneity: $\mathrm{T}^{2}=0.00, \mathrm{I}^{2}=. \%, \mathrm{H}^{2}=$. } & & $0.55[0.34,0.90]$ & \\
\hline \multicolumn{6}{|c|}{ Test of $\theta_{1}=\theta_{j}: Q(0)=0.00, p=$} \\
\hline \multicolumn{6}{|c|}{3 NRP vs. ISC } \\
\hline Del Río & $177 \quad 72$ & 34 & $\longrightarrow$ & $0.36[0.14,0.96]$ & 13.00 \\
\hline Delsuc & 23 & 27 & & $0.47[0.14,1.61]$ & 8.86 \\
\hline Matillon & 13 & 24 & $\longrightarrow$ & $0.72[0.14,3.73]$ & 5.24 \\
\hline Demiselle & 10 & 25 & & $0.27[0.08,0.95]$ & 8.37 \\
\hline Abboud & 2111 & 50 & & $0.23[0.07,0.70]$ & 10.40 \\
\hline Valero & 17 & 2218 & $\longrightarrow$ & $0.12[0.01,1.04]$ & 3.05 \\
\hline \multicolumn{4}{|c|}{ Heterogeneity: $T^{2}=0.00, I^{2}=0.00 \%, H^{2}=1.00$} & $0.33[0.20,0.55]$ & \\
\hline \multicolumn{6}{|c|}{ Test of $\theta_{1}=\theta_{j}: Q(5)=2.62, p=0.76$} \\
\hline \multicolumn{6}{|c|}{4 NRP vs. SRR } \\
\hline Peri & 810 & 13 & & $0.49[0.14,1.77]$ & 8.22 \\
\hline Beato & 314 & 2818 & $\longrightarrow$ & $0.14[0.03,0.55]$ & 7.19 \\
\hline \multicolumn{4}{|c|}{ Heterogeneity: $\mathrm{T}^{2}=0.35, \mathrm{I}^{2}=43.10 \%, \mathrm{H}^{2}=1.76$} & $0.27[0.08,0.93]$ & \\
\hline \multicolumn{6}{|c|}{ Test of $\theta_{1}=\theta_{j}: Q(1)=1.76, p=0.18$} \\
\hline \multicolumn{6}{|c|}{5 NRP vs. TBC } \\
\hline Valero & 17 & 62 & $\longrightarrow$ & $0.05[0.00,0.66]$ & 2.13 \\
\hline \multicolumn{4}{|c|}{ Heterogeneity: $\mathrm{T}^{2}=0.00, \mathrm{I}^{2}=. \%, \mathrm{H}^{2}=$. } & $0.05[0.00,0.66]$ & \\
\hline \multicolumn{6}{|c|}{ Test of $\theta_{1}=\theta_{j}: Q(0)=0.00, p=$. } \\
\hline Overall & & & & $0.36[0.25,0.54]$ & \\
\hline \multicolumn{6}{|c|}{ Heterogeneity: $\mathrm{T}^{2}=0.06, \mathrm{I}^{2}=14.32 \%, \mathrm{H}^{2}=1.17$} \\
\hline \multicolumn{6}{|c|}{ Test of $\theta_{1}=\theta_{j}: Q(9)=9.76, p=0.37$} \\
\hline \multicolumn{6}{|c|}{ Test of group differences: $Q_{0}(3)=5.14, p=0.16$} \\
\hline & & & $1 / 256$ & & \\
\hline
\end{tabular}

Figure 3 Forest plot of meta-analysis of DGF rates of different in situ preservation techniques. Group 2: NRP vs. HRP, Group 3: NRP vs. ISC, Group 4: NRP vs. SRR, Group 5: NRP vs. TBC. HRP, hypothermic regional perfusion; ISC, in situ cooling; NRP, normothermic regional perfusion; SRR, super rapid recovery.

standard DCDs, and they were comparable to, if not better than, the rates with DBDs of all ages. Most studies reported $\mathrm{PNF}$ rates of $0 \%$, with the remainder reporting rates comparable to those for DBDs older than 60 years (26).

Furthermore, the preferred in situ technique for preservation in both controlled and uncontrolled DCD is determined by local transplant program protocols and experience. This recommendation depends on pre-mortem interventions (e.g., cannulation), surgical preferences (e.g., femoral cannulation vs. sternolaparotomy) and logistics (27). Ethical issues limit widespread acceptance and implementation of DCD transplantation.

Kidney transplantation from uDCD has been reintroduced into clinical practice in France since June 2006. In Spain, uDCD has been performed since the late 1980s/early 1990s, while cDCD was implemented nationally in 2012 (28). In addition to being the mandatory in situ organ preservation technique for DCD liver recovery, sub-diaphragmatic 
Table 3 Comparison of graft loss rates in different in situ preservation techniques

\begin{tabular}{|c|c|c|c|c|c|c|c|c|}
\hline Study & Study type & $\begin{array}{l}\text { Study year/ } \\
\text { country }\end{array}$ & $\begin{array}{c}\text { Total } \\
\text { transplants }\end{array}$ & Groups & $\mathrm{n}$ & $\begin{array}{c}\text { Graft loss, } \\
\text { n (\%) }\end{array}$ & OR (95\% Cl) & $P$ \\
\hline \multirow{2}{*}{$\begin{array}{l}\text { Del Río } \\
\text { et al. (1) }\end{array}$} & \multirow[t]{2}{*}{ Cohort } & \multirow[t]{2}{*}{ 2019, Spain } & \multirow[t]{2}{*}{379 uDCD } & In situ cooling & - & - & $5.6(2.7-11.5)^{\mathrm{a}}$ & $0.00^{*}$ \\
\hline & & & & HRP & - & - & - & \\
\hline \multirow{2}{*}{$\begin{array}{l}\text { Matillon } \\
\text { et al. (17) }\end{array}$} & \multirow[t]{2}{*}{ Cohort } & \multirow[t]{2}{*}{ 2017, France } & \multirow[t]{2}{*}{44 uDCD } & In situ cooling & 28 & 2 & \multirow[t]{2}{*}{$1.71(0.11-25.77)$} & \multirow[t]{2}{*}{0.61} \\
\hline & & & & NRP & 16 & 2 & & \\
\hline $\begin{array}{l}\text { Vidal et al. } \\
\text { (23) }\end{array}$ & Cohort & 2016, Spain & 152 uDCD & In situ cooling & - & - & $3.6(1.4-9)^{a}$ & $0.01^{*}$ \\
\hline
\end{tabular}

${ }^{a}$, in situ cooling versus normothermic regional perfusion (ref.); ${ }^{b}$, HRP versus normothermic regional perfusion (ref.). * $\mathrm{P}<0.05 . \mathrm{cDCD}$, controlled donation after circulatory death; UDCD, uncontrolled donation after circulatory death; NRP, normothermic regional perfusion; HRP, hypothermic regional perfusion.

Table 4 Included studies analysing graft survival at 12 or 24 months in different in situ preservation techniques

\begin{tabular}{|c|c|c|c|c|c|c|c|c|}
\hline Study & Study type & $\begin{array}{l}\text { Study year/ } \\
\text { country }\end{array}$ & $\begin{array}{c}\text { Total } \\
\text { transplants }\end{array}$ & Groups & $\mathrm{n}$ & $\begin{array}{c}\text { Graft survival, } \\
n(\%)\end{array}$ & OR (95\% Cl) & $\mathrm{P}$ \\
\hline $\begin{array}{l}\text { Delsuc } \\
\text { et al. (13) }\end{array}$ & Cohort & 2018, France & 64 uDCD & In situ cooling & 32 & $96.8 \%$ & $1(0.12-80.99)$ & 1 \\
\hline \multirow{2}{*}{$\begin{array}{l}\text { Peri et al. } \\
\text { (14) }\end{array}$} & \multirow[t]{2}{*}{ Cohort } & \multirow[t]{2}{*}{ 2018, Spain } & \multirow[t]{2}{*}{39 cDCD } & Super rapid recovery & 21 & $21(100 \%)$ & \multirow[t]{2}{*}{-} & \multirow[t]{2}{*}{0.2738} \\
\hline & & & & NRP & 18 & $17(94.4 \%)$ & & \\
\hline $\begin{array}{l}\text { Valero } \\
\text { et al. (22) }\end{array}$ & Cohort & 2000, Spain & 56 DCD & $\begin{array}{l}\text { Cardiopulmonary bypass } \\
\text { (CPB) techniques }\end{array}$ & 16 & $86 \%$ & - & - \\
\hline
\end{tabular}

a , including total body cooling and normothermic recirculation. Graft survival at 12 months: Peri et al. Graft survival at 24 months: Delsuc et al. and Valero et al. DCD, donation after circulatory death; UDCD, uncontrolled donation after circulatory death; NRP, normothermic regional perfusion.

Table 5 Included studies analysing acute rejection in different $i n$ situ preservation techniques.

\begin{tabular}{|c|c|c|c|c|c|c|c|c|}
\hline Study & Study type & $\begin{array}{l}\text { Study year/ } \\
\text { country }\end{array}$ & $\begin{array}{c}\text { Total } \\
\text { transplants }\end{array}$ & Groups & $\mathrm{n}$ & $\begin{array}{c}\text { Acute rejection, } \\
n(\%)\end{array}$ & OR $(95 \% \mathrm{Cl})$ & $\mathrm{P}$ \\
\hline $\begin{array}{l}\text { Delsuc } \\
\text { et al. (13) }\end{array}$ & Cohort & 2019, France & 64 uDCD & In situ cooling & 32 & $6(19 \%)$ & $0.80(0.17-3.60)$ & 0.74 \\
\hline
\end{tabular}

ECMO is considered by many teams to be superior to a double- balloon triple-lumen (DBTL; Gillot's) catheter for kidney graft outcome. The former technique has gradually replaced the latter (19). Thus, an additional advantage of in situ normothermic regional perfusion is the combined benefit for other abdominal organs with enhanced organ utilization and improvement of DCD graft results.

DGF is an early complication after kidney transplantation with a negative impact on allograft outcomes. There are several studies (Sánchez-Fructuoso et al. and Lee et al.) comparing DCD kidney $v s$. kidneys recovered from DBD $(29,30)$. When compared with the latter, DCD kidneys have 


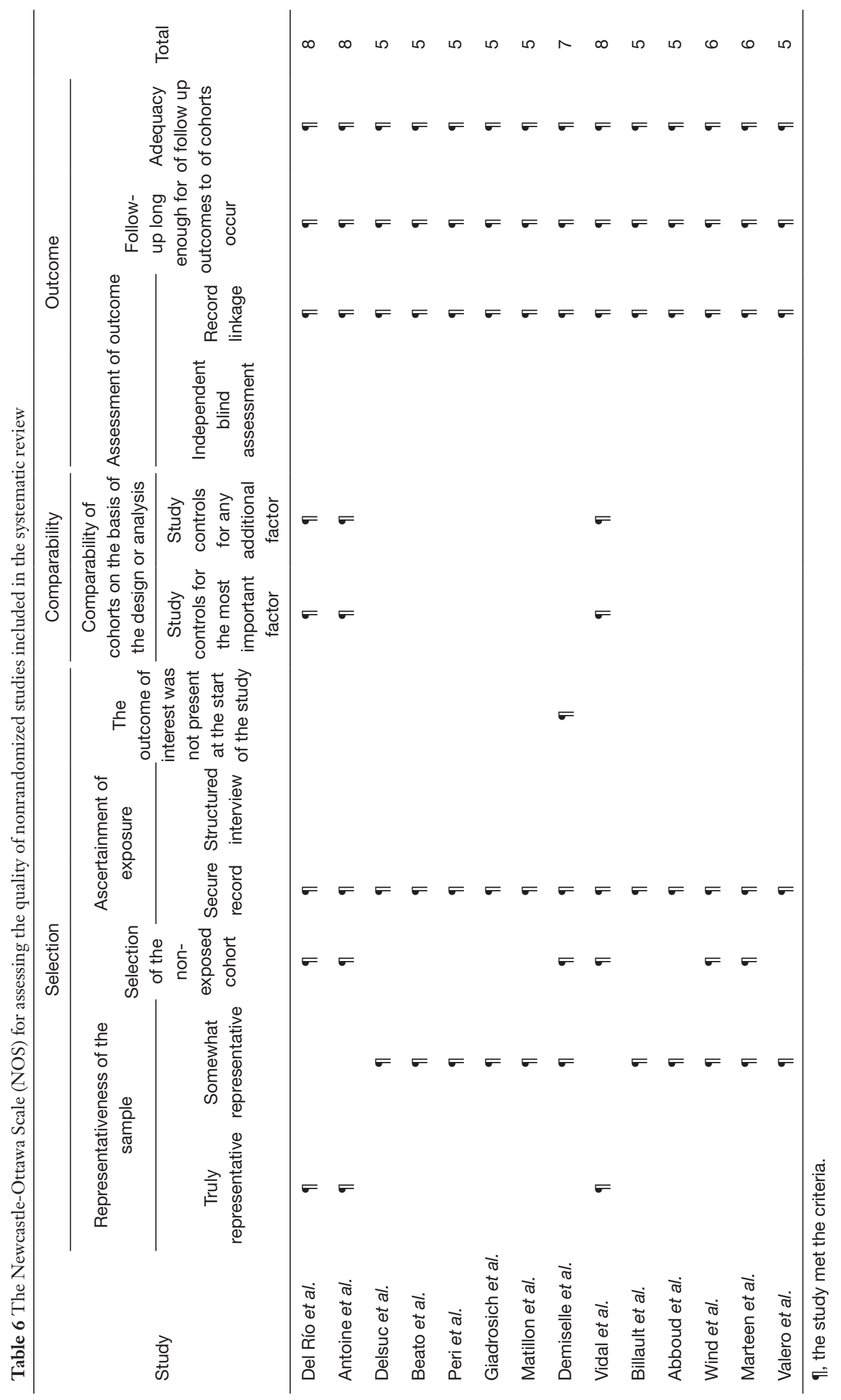


increased rates of DGF and PNF, mainly due to increased warm ischaemia time during recovery. Miñambres et al. investigated 37 kidney transplantations after NRP and compared their clinical outcomes to DBD kidney transplant outcomes. They showed that graft survival was similar to graft survival of a DBD kidney with 5\% PNF and 27\% DGF (31).

Valero et al. found that NRP reduces PNF and DGF and they published these results in 2000 (22). Since then, RCTs have not been performed because there is a certain consensus on the superiority of NRP in liver transplantation, and it is the preservation method of choice in many DCD programs. As a consequence, when thoracic and other abdominal organs from deceased donors are retrieved during a multiorgan procedure, a RCT is not possible.

Farney et al. compared 25 kidney transplants after hypothermic regional perfusion to kidney transplants retrieved with the SRR technique. They concluded that kidney transplants after HRP had lower rates of DGF and shorter hospitalization times. In conclusion, HRP could possibly reduce the incidence of DGF and hospitalization duration after kidney transplantation when compared with the SRR technique. Graft survival after NRP resembles DBD graft survival, which has been shown to be similar to DCD kidney graft survival using the SRR technique. However, NRP may reduce the incidence of DGF and PNF (28). Our meta-analysis revealed that grafts preserved using NRP could be superior to those preserved using other techniques regarding DGF rates (0.36, 95\% CI: 0.25-0.54), and no heterogeneity was found for the effect $(\mathrm{P}=0.37$; $\mathrm{I}^{2}=14.32 \%$ ) between groups. In contrast, PNF rate does not appear to be improved using this technique according to the pooled OR obtained from the meta-analysis 0.83 (95\% CI: $0.40-1.71)$.

The NRP-team in the United Kingdom (Oniscu et al.) published their first experience in 2014. Forty-nine patients were transplanted, including 32 kidney transplants, 11 liver transplants, 2 combined pancreas-kidney transplants, 1 islet transplant and 3 double lung transplants. The authors concluded that NRP facilitated organ recovery (32). The Spanish group (Del Río et al.) published their experience of 511 kidney transplants from uncontrolled DCD donors and they showed improved graft survival after using NRP or HRP and preferable to in situ cooling of kidneys from uDCD donors (23). In a study by Demiselle et al., NRP in uDCD transplants led to a lower DGF rate and better renal graft function 2 years after transplantation compared to cold stored DCD kidneys (18).
Graft loss is identified as one of the critically important outcome domains in kidney transplantation for health professionals, along with mortality, graft function and chronic graft rejection (33). However, this outcome has been scarcely addressed in the literature. Del Río et al. (1) analysed the factors associated with death-censored graft loss during the first year after transplantation, and they found that the donor age of 60 years or older, in situ cooling of kidneys ( $v s$. NRP/HRP) and a recipient's history of previous kidney transplants are factors significantly associated with this outcome.

The findings from the few heterogeneous retrospective studies reported to date indicate that NRP offers benefits when compared with conventional in situ cold preservation. The results of a systematic review of the literature highlight the promising results of NRP compared to a super-rapid recovery procedure or in situ cooling, with reduced DGF rates. However, evidence is weak due to the heterogeneity of studies included and these results should thus be treated with caution.

The small and scarce retrospective studies, together with the heterogeneous outcomes, are limitations to this study.

\section{Conclusions}

Management of the donor can have a significant impact on recipient outcomes after kidney transplantation. The findings concerning in situ preservation techniques on the different graft outcomes suggest that DGF rates could be reduced by using NRP compared to other preservation techniques.

\section{Acknowledgments}

Funding: None.

\section{Footnote}

Reporting Checklist: The authors have completed the PRISMA reporting checklist. Available at https://dx.doi. org/10.21037/tau-21-236

Peer Review File: Available at https://dx.doi.org/10.21037/ tau-21-236

Conflicts of Interest: All authors have completed the ICMJE uniform disclosure form (available at https://dx.doi. org/10.21037/tau-21-236). The authors have no conflicts of 
interest to declare.

Ethical Statement: The authors are accountable for all aspects of the work in ensuring that questions related to the accuracy or integrity of any part of the work are appropriately investigated and resolved.

Open Access Statement: This is an Open Access article distributed in accordance with the Creative Commons Attribution-NonCommercial-NoDerivs 4.0 International License (CC BY-NC-ND 4.0), which permits the noncommercial replication and distribution of the article with the strict proviso that no changes or edits are made and the original work is properly cited (including links to both the formal publication through the relevant DOI and the license). See: https://creativecommons.org/licenses/by-nc-nd/4.0/.

\section{References}

1. Del Río F, Andrés A, Padilla M, et al. Kidney transplantation from donors after uncontrolled circulatory death: the Spanish experience. Kidney Int 2019;95:420-8.

2. Lomero M, Gardiner D, Coll E, et al. Donation after circulatory death today: an updated overview of the European landscape. Transpl Int 2020;33:76-88.

3. Tatapudi VS, Montgomery RA. Therapeutic Modulation of the Complement System in Kidney Transplantation: Clinical Indications and Emerging Drug Leads. Frontiers in Immunology. Available online: https://www.frontiersin. org/articles/10.3389/fimmu.2019.02306/full

4. Dunne K, Doherty P. Donation after circulatory death. Contin Educ Anaesth Crit Care Pain 2011;11:82-6.

5. Smith M, Dominguez-Gil B, Greer DM, et al. Organ donation after circulatory death: current status and future potential. Intensive Care Med 2019;45:310-21.

6. Zanierato M, Dondossola D, Palleschi A, et al. Donation after circulatory death: possible strategies for in-situ organ preservation. Minerva Anestesiol 2020;86:984-91.

7. Lomero M, Gardiner D, Coll E, et al. Donation after circulatory death: An updated description of the European landscape. Transplantation 2018;102:S386.

8. Jericho BG. Organ Donation After Circulatory Death: Ethical Issues and International Practices. Anesth Analg 2019;128:280-5.

9. Barrou B, Billault C, Nicolas-Robin A. The use of extracorporeal membranous oxygenation in donors after cardiac death. Curr Opin Organ Transplant 2013;18:148-53.
10. Hessheimer AJ, Billault C, Barrou B, et al. Hypothermic or normothermic abdominal regional perfusion in highrisk donors with extended warm ischemia times: impact on outcomes? Transpl Int 2015;28:700-7.

11. Hessheimer AJ, Coll E, Torres F, et al. Normothermic regional perfusion vs. super-rapid recovery in controlled donation after circulatory death liver transplantation. J Hepatol 2019;70:658-65.

12. Antoine C, Savoye E, Gaudez F, et al. Kidney Transplant From Uncontrolled Donation After Circulatory Death: Contribution of Normothermic Regional Perfusion. Transplantation 2020;104:130-6.

13. Delsuc C, Faure A, Berthiller J, et al. Uncontrolled donation after circulatory death: comparison of two kidney preservation protocols on graft outcomes. BMC Nephrol 2018;19:3.

14. Peri Ll, Ruiz A, Sousa E, et al. Controlled donors after cirulatory death: Comparison between normothermic regional perfusion and super rapid retrieval in renal transplantation. Eur Urol Suppl 2018;17:e960-1.

15. Beato S, Fiol M, Etchevarry Giadrosich B, et al. Kidneys from Maastricht category III: Does NECMO influence on DGF? Eur Urol Suppl 2018;17:e1756-7.

16. Etchevarry Giadrosich B, Riera M, Riera Canals L, et al. Kidney preservation techniques in controlled circulatory death: NECMO and ultra-rapid retrieval. J Urol 2018;199:e545-6.

17. Matillon X, Danjou F, Petruzzo P, et al. Hypothermic pulsatile preservation of kidneys from uncontrolled deceased donors after cardiac arrest - a retrospective study. Transpl Int 2017;30:1284-91.

18. Demiselle J, Augusto JF, Videcoq M, et al. Transplantation of kidneys from uncontrolled donation after circulatory determination of death: comparison with brain death donors with or without extended criteria and impact of normothermic regional perfusion. Transpl Int 2016;29:432-42.

19. Abboud I, Viglietti D, Gaudez F, et al. Learning curve of ECMO in DCD (better the devil you know?). Am J Transplant 2013;13:397.

20. Billault C, Thuret R, Van Glabeke E, et al. Kidney transplantation from non-heat beating donors: 3 -year results. Transpl Int 2013;26:58.

21. Wind J, Hoogland ER, van Heurn LW. Preservation techniques for donors after cardiac death kidneys. Curr Opin Organ Transplant 2011;16:157-61.

22. Valero R, Cabrer C, Oppenheimer F, et al. Normothermic recirculation reduces primary graft dysfunction of kidneys 
obtained from non-heart-beating donors. Transpl Int 2000;13:303-10.

23. Del Río F, Andrés A, Padilla M, et al. Kidney transplantation from uncontrolled donors after circulatory death: the Spanish experience. Transplantation 2016;100:S92-3.

24. Peng JC, Ding J, He ZY, et al. The efficacy of extracorporeal membrane oxygenation in liver transplantation from non-heart-beating donors: A systemic review and meta-analysis. Medicine (Baltimore) 2019;98:e14722.

25. Branchereau J, Hunter J, Friend P, et al. Pancreas preservation: clinical practice and future developments. Curr Opin Organ Transplant 2020;25:329-35.

26. Shapey IM, Muiesan P. Regional perfusion by extracorporeal membrane oxygenation of abdominal organs from donors after circulatory death: a systematic review. Liver Transpl 2013;19:1292-303.

27. Shemie SD, Baker AJ, Knoll G, et al. National recommendations for donation after cardiocirculatory death in Canada: Donation after cardiocirculatory death in Canada. CMAJ 2006;175:S1.

28. Hessheimer AJ, Gastaca M, Miñambres E, et al. Donation after circulatory death liver transplantation: consensus

Cite this article as: Artiles Medina A, Burgos Revilla FJ, Álvarez Nadal M, Muriel García A, Álvarez Díaz N, Gómez Dos Santos V. Comparison of in situ preservation techniques for kidneys from donors after circulatory death: a systematic review and meta-analysis. Transl Androl Urol 2021;10(8):3286-3299. doi: 10.21037/tau-21-236 statements from the Spanish Liver Transplantation Society. Transpl Int 2020;33:902-16.

29. Sánchez-Fructuoso AI, Marques M, Prats D, et al. Victims of cardiac arrest occurring outside the hospital: a source of transplantable kidneys. Ann Intern Med 2006;145:157-64.

30. Lee CY, Tsai MK, Ko WJ, et al. Expanding the donor pool: use of renal transplants from non-heart-beating donors supported with extracorporeal membrane oxygenation. Clin Transplant 2005;19:383-90.

31. Miñambres E, Suberviola B, Dominguez-Gil B, et al. Improving the Outcomes of Organs Obtained From Controlled Donation After Circulatory Death Donors Using Abdominal Normothermic Regional Perfusion. Am J Transplant 2017;17:2165-72.

32. Oniscu GC, Randle LV, Muiesan P, et al. In situ normothermic regional perfusion for controlled donation after circulatory death--the United Kingdom experience. Am J Transplant 2014;14:2846-54.

33. Sautenet B, Tong A, Manera KE, et al. Developing Consensus-Based Priority Outcome Domains for Trials in Kidney Transplantation: A Multinational Delphi Survey With Patients, Caregivers, and Health Professionals. Transplantation 2017;101:1875-86. 


\section{Supplementary}

\section{Search strategy}

\section{EMBASE}

\section{SourcesEmbase, MEDLINE}

Query('kidney transplantation'/exp OR 'renal transplantation':ab,ti OR 'kidney transplant':ab,ti OR 'kidney graft'/exp OR 'non heart beating donor'/exp OR 'controlled donation':ab,ti OR 'uncontrolled donation':ab,ti OR 'cdcd':ab,ti OR 'udcd':ab,ti) AND ('organ preservation'/exp OR 'organ perfusion'/exp OR 'in situ preservation':ab,ti OR 'normothermic regional perfusion'/exp OR 'normothermic recirculation':ab,ti OR 'hypothermic perfusion'/exp OR 'in situ cooling':ab,ti OR 'double balloon catheter':ab,ti) AND [embase]/lim

\#10 AND \#19 AND [embase]/lim

3,182

\#20

\#10 AND \#19

3,565

\#19

\#11 OR \#12 OR \#13 OR \#14 OR \#15 OR \#16 OR \#17 OR \#18

108,930

\#18

'double balloon catheter':ab,ti

294

\#17

'in situ cooling':ab,ti

74

\#16

'hypothermic perfusion'/exp

25

\#15

'normothermic recirculation':ab,ti

29

\#14

'normothermic regional perfusion'/exp

29

\#13

'in situ preservation':ab,ti

82

\#12

'organ perfusion'/exp

96,396

\#11

'organ preservation'/exp

14,103

$\# 10$

\#1 OR \#2 OR \#3 OR \#4 OR \#5 OR \#6 OR \#7 OR \#8 OR \#9

161,822

\#9

'udcd':ab,ti

133 


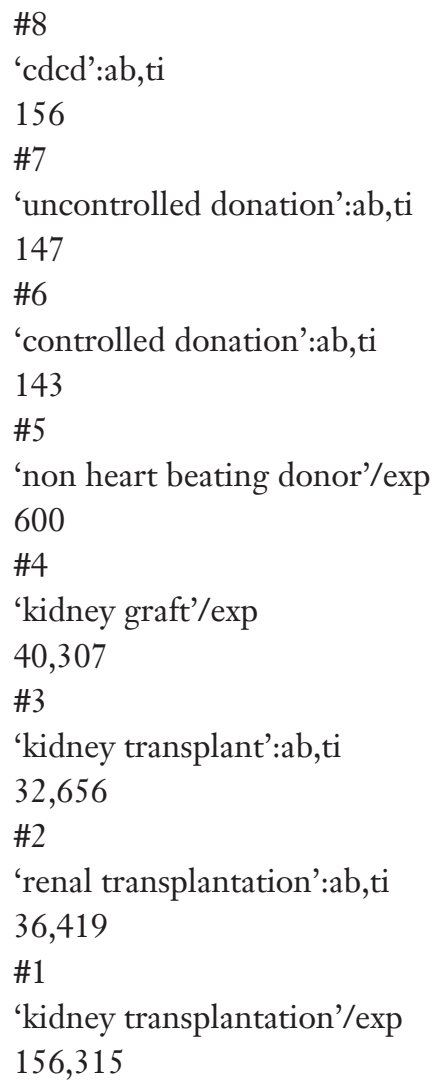

\section{PubMed}

("Kidney Transplantation”[Mesh] OR "Kidney transplant”[Title/Abstract] OR "renal transplantation”[Title/Abstract] OR “Kidney graft”[Title/Abstract] OR "kidney transplants”[Title/Abstract] OR “controlled donation”[Title/Abstract] OR "uncontrolled donation"[Title/Abstract] OR ("death cardiac"[Title/Abstract] AND "donation"[Title/Abstract]) OR "DCD”[Title/Abstract] OR “cDCD”[Title/Abstract] OR “uDCD”[Title/Abstract]) AND ("Organ Preservation”[Mesh] OR "Perfusion”[Mesh] OR "in situ Preservation”[Title/Abstract] OR "normothermic regional perfusion”[Title/Abstract] OR "normothermic recirculation"[Title/Abstract] OR "NRP”[Title/Abstract] OR "super-rapid recovery"[Title/Abstract] OR "in situ cold perfusion"[Title/Abstract] OR "ICP"[Title/Abstract] OR "in situ cooling"[Title/Abstract] OR "hypothermic regional perfusion" [Title/Abstract] OR “double-balloon triple-lumen catheter"[Title/Abstract] OR "DBTL”[Title/Abstract])

\section{LILACS}

(tw:("trasplante de riñon" OR "injerto renal" OR "trasplante renal" OR "donacion controlada" OR "donacion no controlada")) AND (tw:(preservacion OR "perfusion regional normotermica" OR "perfusion hipotermica" OR "extraccion super rapida"))

\section{COCHRANE}

Search Name:

Date Run: 16/04/2020 19:01:24

Comment: 


\section{ID Search Hits}

\#1 MeSH descriptor: [Kidney Transplantation] explode all trees 3507

\#2 ("Kidney transplant"):ti,ab,kw 2877

\#3 ("renal transplantation"):ti,ab,kw 2561

\#4 ("Kidney Grafting”):ti,ab,kw 1

\#5 ("Kidney Graft”):ti,ab,kw 1976

\#6 (“controlled donation”):ti,ab,kw 4

\#7 ("uncontrolled donation"):ti,ab,kw 1

\#8 MeSH descriptor: [Organ Preservation] explode all trees 171

\#9 MeSH descriptor: [Perfusion] explode all trees 883

\#10 (“in situ Preservation"):ti,ab,kw 3

\#11 ("nRP"):ti,ab,kw 107

\#12 ("in situ cold perfusion"):ti,ab,kw 1

\#13 ("in situ cooling"):ti,ab,kw 2

\#14 \#1 OR \#2 OR \#3 OR \#4 OR \#5 OR \#6 OR \#7 7503

\#15 \#8 OR \#9 OR \#10 \#11 OR \#12 OR \#13 1006

\#16 \#14 AND \#15 80 